\title{
EDITORIAL FOR THE SPECIAL ISSUE ON IT AND CLIMATE CHANGE
}

\section{A SELECTION OF PAPERS FROM THE CARBON-CENTRIC COMPUTING NATIONAL RESEARCH SUMMIT HELD AT THE UNIVERSITY OF WOLLONGONG, NOVEMBER}

24, 2008.

\section{Aditya Ghose \\ Helen Hasan Trevor Spedding}

\section{Carbon-Centric Computing Initiative}

University of Wollongong

\begin{abstract}
Climate change is a key topic of global concern, causing vigorous debate at local, national and international levels. The Carbon-Centric Computing Initiative (CCCI) was set up in 2008 by a cross-disciplinary group of researchers focused on the problem of climate change and using our capability as IT and related professionals to reduce our carbon footprint. A CCCI National Summit was held on November 24, 2008 where an international team of experts presented on a range of topics, methods and approaches for conducting research into positive application of IT in areas affecting the environment. This special issue of AJIS contains a selection of papers from those who took part in the summit demonstrating the quality and breadth of research and potential research in this area.
\end{abstract}

The discipline of Information Systems (IS) has since recognized that it has a role to play in the current debate on climate change with several relevant tracks and papers at IS conferences (ACIS2009, ECIS2009, PACIS2009, AMCIS2009, ICIS2009) and special issues in 2009 of leading journals (eg Strategic Information Systems, Information and Management). The current discourse on information technology (IT) and climate change views IT in a negative light, as a polluter (see the Australian Computer Society's Policy on Green $\mathrm{ICT}^{1}$ ). What remains unrecognised is the critical role of IT in providing a range of tools to model, manage and optimize the 'planet earth' supply chain. We believe that enabled by information systems, efficiencies can be achieved that reduce carbon emission in almost all areas of human activity as well as demonstrate to others how and why this is done.

The collection of papers highlights the variety of issues and approaches that researchers in Information Systems can bring to the challenges of environmental sustainability. These range

\footnotetext{
${ }^{1}$ http://www.acs.org.au/acs_policies/docs/2007/greenictpolicy.pdf
} 
across the IS spectrum offering simple and sophisticated ways of supporting, enabling, optimising, monitoring, modelling, predicting and/or controlling a whole range of human activities on both a micro and macro-scale with benefits not only to the environment but also efficiencies, speed and cost reductions.

This selection of papers begins with an article describing "A Framework for Carbon-Aware Business Process Management" by four authors: Aditya Ghose, Konstantin Hoesch-Klohe, Lothar Hinsche, Lam-Son Le. The paper begins with the message central to this whole collection that we aim here to move on from the current green computing discourse where the emphasis is on the IT industry as a polluter and so we should only focus on reducing the carbon footprint of computing infrastructures such as data centres, server farms, organizational IT infrastructure and even individual computers. The authors present IT as a source of solutions to the climate change problem providing technologies that enable efficiencies and optimization in operational processes of almost every conceivable variety. This paper takes Business Process Management (BPM) technology, with its focus on understanding, modelling and improving business processes, as a starting point for optimising existing business process to reduce their emissions.

The second paper, "Web 2.0 Solutions to Wicked Climate Change Problems" by Alanah Kazlauskas and Helen Hasan, investigates the use of Web 2.0 applications as tools that allow people to communicate, coordinate and collaborate in ways that reduce their carbon footprint. These authors see Climate Change as a wicked problem where issues ill-defined and initiative have conflicting objectives. Here simple solutions are rarely possible and this paper describes a way to take a holistic and multifaceted way forward. This sees Web 2.0 as providing tools in organisational ecosystem that can best be understood through a comprehensive sense-making framework.

The third paper, Simulation Modelling and Strategic Change: Creating the Sustainable Enterprise, by Patrick Dawson and Trevor Spedding presents change management frameworks which facilitate productivity and environmental improvements in order to create a sustainable enterprise. Traditionally, business innovations have focused on improving practical problems such as better tools, products and techniques to achieve competitive advantage. The authors contend that in the face of increasing economic, social and environmental challenges, contemporary societies are looking towards innovations that resolve these concerns, and in conjunction, improve the well-being of people. These proposed change management frameworks can be integrated with simulation models to provide dynamic roadmaps which provide an organisation with clear directions to implement operational, technological, environmental and social change necessary so that the optimal benefits from the change process can be fully realised.

The fourth paper, "Using Design as a Boundary Spanner Object in Climate Change Mitigation Projects", comes from the work of Walter Fernandez who brings an IS perspective to a multidisciplinary scientific team working on fascinating technologies being developed to capture solar energy as plant biomass in a variety of first generation "energy" crops. The paper describes how understandings of complex systems development, project management and design science from the field of IS, can contribute to the work of the team. This is done through the use of an iterative method based on the FormIT model where knowledge increases through iterative interactions between phases and people with diverse competences and perspectives.

The fifth paper, "The Social Shaping of Technology: Lessons for Eco-Innovators", comes from Bob Brown and David Mercer who bring insights from the interdisciplinary field of STS (Science and Technology Studies or Science Technology and Society) to assist eco-innovators in the IT sector. 
They bring ideas from the social shaping of technology literatures to the discourse on successful innovation in the areas of IS and environmental concerns. This involves thinking in terms of fluid boundaries between the technical and the social, identifying how users of the technology can play an important role in innovation thereby generating new forms of knowledge across the technical, social and economic domains

The sixth paper, "The greening of the organisational IT - what makes a difference", by Ben Huo and Geoff Dick proposes and empirically tests a model of factors influencing the 'greening' of organisational IT and IS. These factors include motivational pressures, organisational factors and technological constraints. The results of their empirical study conducted by means of an online survey tend to suggest that green IT efforts are motivated by employees' sense of social responsibility within organisations that have the capability to adapt rather than by issues of economics of technologies. This counters most of the popular wisdom that suggests that organisations are mainly concerned with impacts on the bottom line.

The final paper, "Computational Intelligence for Carbon-Centric Computing" by John Fulcher, takes us into a possible technology of the future and demonstrates how broad are the areas of IT and IS that can be brought to bear on the problems of climate change. The paper describes computational Intelligence techniques for pattern-recognition and modelling leading to the fascinating possibilities of carbon-based rather than silicon-based computational machines. We can now only speculate on what may be the implications of this for cost, performance, potential applications and for the environment. 